\title{
The Properties of Water in the Pressure-Temperature Landscape
}

\section{Journal Article}

Author(s):

Mathys, Alexander (1); Knorr, D.

Publication date:

2009

Permanent link:

https://doi.org/10.3929/ethz-b-000110549

Rights / license:

In Copyright - Non-Commercial Use Permitted

Originally published in:

Food Biophysics 4(2), https://doi.org/10.1007/s11483-009-9103-1 


\title{
The Properties of Water in the Pressure-Temperature Landscape
}

\author{
A. Mathys $\cdot$ D. Knorr
}

Received: 7 August 2008 / Accepted: 11 February 2009/Published online: 12 March 2009

(C) Springer Science + Business Media, LLC 2009

\begin{abstract}
Water represents the major component of most food systems. During thermal or high-pressure processing, physical and chemical properties of water are changed. The $\mathrm{p}-\mathrm{T}$ diagram represents an obvious presentation of isoproperty lines and their pressure and temperature dependencies. In this work, 15 different properties of pure water are shown as isoproperty lines in the pressure-temperature landscape. By using functional relationships from the "International Association for the Properties of Water and Steam" and databases from the "National Institute of Standards and Technology," highest accuracy is guaranteed. Applying the generated graphs, a compact overview is given and a wide range of thermal and high-pressure processes can easily be compared. The different pressure and temperature dependencies of all properties showed the complexity of medium conditions during thermal and high-pressure processing. An extended understanding of pressure-temperature dependencies will improve process concepts as well as industrial applications at high temperature and high isostatic pressure.
\end{abstract}

Keywords Water $\cdot \mathrm{p}-\mathrm{T}$ diagram $\cdot$ High pressure .

Thermal treatment

A. Mathys $(\bowtie) \cdot$ D. Knorr

Department of Food Biotechnology and Food Process Engineering,

Berlin University of Technology,

Koenigin-Luise-Str. 22,

14195 Berlin, Germany

e-mail: alexander.mathys@rdls.nestle.com

Present Address:

A. Mathys

Nestlé Research Centre Lausanne,

Vers-Chez-Les-Blanc,

1000 Lausanne 26, Switzerland

\section{Introduction}

Water is essential to all known forms of life. It represents the major component of most food systems and is typically used as pressure transmitting medium. In food processing, the application of high isostatic pressure as emerging technology has steadily increased during the past 10 years, and in 2008, 125 industrial installations existed worldwide with volumes ranging from 35 to $420 \mathrm{~L}$ and an annual production volume of more than 200,000 tons (Tonello Samson, C., NC Hyperbaric, Spain, 2008, personal communication). The fast-growing user community in food technology needs concise overviews about process parameters in the $\mathrm{p}-\mathrm{T}$ domain. Data for the pressure and temperature dependencies of water are available in complex tables and functional relationships. This work presents the pressure and temperature dependencies of 15 fundamental parameters as most obvious presentation form with isoproperty lines in the $\mathrm{p}-\mathrm{T}$ landscape. These data enable an adequate comparison of different thermal or high-pressure processes with chemical or biological changes in the $\mathrm{p}-\mathrm{T}$ domain. Some biological research studies worked up to $1,200-1,400 \mathrm{MPa},{ }^{1,2}$ and innovative laboratory-scale equipment for basic studies is developed up to $1,400 \mathrm{MPa}$ (by using an extra booster system) and $140{ }^{\circ} \mathrm{C} .{ }^{3}$ Hence, thermodynamic, material, and transport properties at these extreme conditions need to be estimated.

\section{Material and Methods}

Extensive data and formulations of the main thermodynamic properties of water are available from the "International Association for the Properties of Water and Steam" (IAPWS) and in the database from the "National Institute of 
Standards and Technology" (NIST). The functional relationships for the pressure and temperature dependencies of density, $\rho$, internal energy, $u$, enthalpy, $h$, Helmholtz free energy, $f$, Gibbs free energy, $g$, entropy, $s$, and speed of sound, $c$, are accurate up to $1,000 \mathrm{MPa}$ and $1,000{ }^{\circ} \mathrm{C} .{ }^{4}$ Material properties in the pressure and temperature landscape can be obtained by derivation of Eqs. 1, 2, and 3 .

According to the first fundamental theorem of thermodynamics and for a constant pressure, isobaric heat capacity, $c_{\mathrm{p}}$, is usually defined as:

$c_{\mathrm{p}} \equiv\left(\frac{\partial h}{\partial T}\right)_{\mathrm{p}}=T\left(\frac{\partial s}{\partial T}\right)_{\mathrm{p}}$

The isobaric coefficient of thermal expansion can be defined as ${ }^{5}$ :

$\alpha_{p} \equiv-\frac{1}{v}\left(\frac{\partial v}{\partial T}\right)_{\mathrm{p}}=-\frac{1}{\rho}\left(\frac{\partial \rho}{\partial T}\right)_{\mathrm{p}}$

with the specific volume $v$.

Isothermal compressibility $\beta_{\mathrm{T}}$ is defined by Eq. $3^{5}$ :

$\beta_{T} \equiv-\frac{1}{v}\left(\frac{\partial v}{\partial p}\right)_{T}=-\frac{1}{\rho}\left(\frac{\partial \rho}{\partial p}\right)_{T}$.

These properties are seen to be the three possible second derivatives of the Gibbs free energy with respect to temperature and pressure.

The functional relationship for the pressure and temperature dependencies of the relative static permittivity, $\varepsilon$, is given up to $1,000 \mathrm{MPa}$ and $800{ }^{\circ} \mathrm{C}$.

By using the second law of thermodynamics, which derives a relation for enthalpy, entropy, and temperature (Eq. 1), the adiabatic-isentropic heating (Eq. 4) of a system can be obtained by combining Eq. 1 with the basic equations for the compressibility of a system (Eq. 3) at constant pressure

$\left(\frac{\partial T}{\partial p}\right)_{S}=\frac{\beta_{T} T}{c_{p} \rho}$.

The adiabatic heating of water at different initial temperatures was obtained by an iteration loop (MathCAD 2001i Professional, MathSoft Engineering \& Education, Inc., USA).

By using the regression equation from Marshall and Frank, ${ }^{7}$ the negative logarithm of the ion product $K_{\mathrm{w}}\left[\left(\mathrm{mol} \mathrm{kg}^{-1}\right)^{2}\right]$ of water substance (Eq. 5) can be calculated with an absolute deviation of \pm 0.01 units at $T<200{ }^{\circ} \mathrm{C}$ and vapor pressure (max. possible relative error $0.08 \%$ ) as well as within \pm 0.03 units at pressures up to $1,000 \mathrm{MPa}$ when the temperature is below $250{ }^{\circ} \mathrm{C}$ (max. possible relative error $0.33 \%$,

$-\log _{10}\left(K_{W}\right)=-\log _{10}\left(\left[\mathrm{H}_{3} \mathrm{O}^{+}\right] \times\left[\mathrm{OH}^{-}\right]\right)$ with the oxonium $\left[\mathrm{H}_{3} \mathrm{O}^{+}\right]$and hydroxide $\left[\mathrm{OH}^{-}\right]$ion concentrations.

Functional relationships for the transport properties thermal conductivity, $\lambda$, and dynamic viscosity, $\eta$, are given up to $400 \mathrm{MPa} / 125{ }^{\circ} \mathrm{C}^{8}$ and $500 \mathrm{MPa} / 150{ }^{\circ} \mathrm{C}^{8}$ respectively (IAPWS). Using the NIST databases 10 or 23 (NIST STEAM or NIST REFPROP, US Department of Commerce, USA), pressure ranges up to $1,000 \mathrm{MPa}$ can be obtained.

In this work, data were extrapolated up to $1,400 \mathrm{MPa}$, which presents the current limit in food technology. ${ }^{2,3,9}$

Using a Boolean logic as complete system for logical operations with the function "equal to operator"(operator = [bold] in MathCAD 2001i Professional, MathSoft Engineering \& Education, Inc.), it was possible to search the pressure or temperature conditions for a fixed water property value. The fixed water property value was connected to the functional relationship by the "equal to operator" function [e.g., fixed water property value $=$ function $(p, T)]$. This procedure enabled the generation of isoproperty lines in the pressure and temperature landscape. The thermal conductivity, $\lambda$, and dynamic viscosity, $\eta$, at higher pressure levels was modeled using a linear interpolation function of the isothermal pressure dependence. The specific volumetric work, $w(p, T)$, in pure water was calculated with Eq. 6,

$$
\int_{A}^{B} d w=\int_{A}^{B} p v \beta_{\mathrm{T}} d p
$$

with the volumetric work $d w$ from $A$ to $B$.

The data for the isothermal specific volumetric work were also modeled with a linear interpolation function. Using the mentioned Boolean operation (MathCAD 2001i Professional, MathSoft Engineering \& Education, Inc.), it was possible to search the pressure at constant temperature for a fixed $\lambda, \eta$, and $w$ value. The presentation of isoproperty lines in the $\mathrm{p}-\mathrm{T}$ landscape was arranged by the Origin 7SR1 software (OriginLab Corporation, USA).

\section{Results and Discussion}

Bridgman $^{5,10}$ was the first to determine the phase diagram of water as function of temperature and pressure. The phase transition lines with adiabatic lines due to compression of water and its different ice modifications, according to Bridgman, are shown in Figure 1a. At present, 12 different crystal structures plus two amorphous states are known. At the transition from the liquid to the solid state, Ice I represents a specialty since only this ice modification shows a positive volume change $\Delta V$. Lower initial temperatures have significantly lower (approximately $2 \mathrm{~K} / 100 \mathrm{MPa}$ ) temperature increases due to compression than higher starting temperatures (up to $5 \mathrm{~K} / 100 \mathrm{MPa}$ over $80^{\circ} \mathrm{C}$ ). A temperature rise is 
Fig. 1 a Phase diagram ${ }^{5,10}$ with different ice modifications and $\mathbf{b}$ density, $\rho\left(\mathrm{kg} \mathrm{m}^{-3}\right)$, with adiabatic lines due to compression (dashed line) of water in the $\mathrm{p}-\mathrm{T}$ landscape

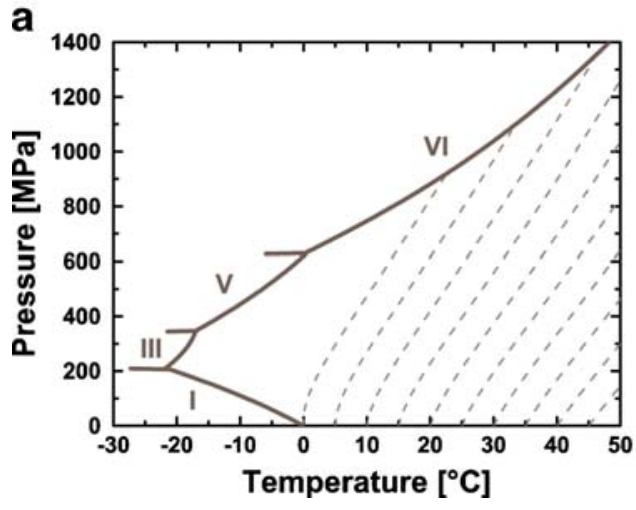

accompanied by a dissipation of heat within and through the pressure vessel, which is dependent on the vessel size, rate of compression, heat transfer parameters, as well as initial and boundary conditions.

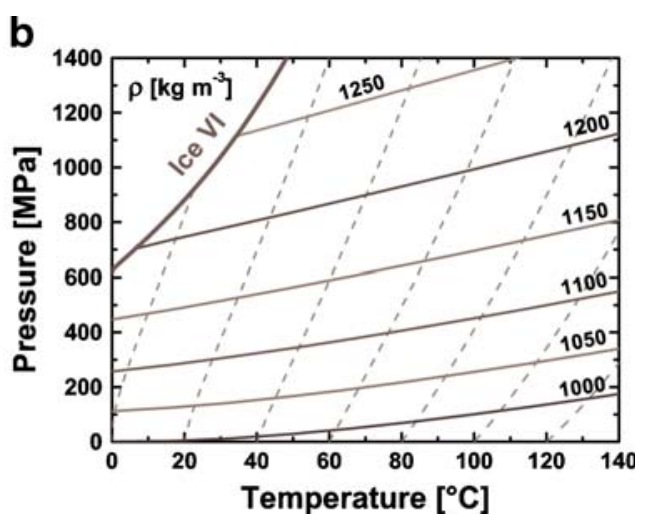

Fig. 2 Fundamental thermodynamic parameters with adiabatic lines due to compression (dashed line) of water in the $\mathrm{p}-\mathrm{T}$ landscape with internal energy, $u$ (a), enthalpy, $h$ (b), Helmholtz free energy, $f(\mathbf{c})$, Gibbs free energy, $g(\mathbf{d})$, entropy, $s(\mathbf{e})$, and the speed of sound, $c(\mathbf{f})$ a

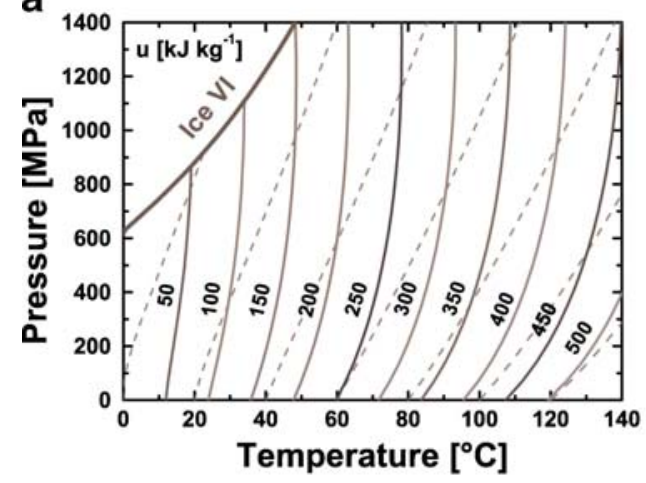

C

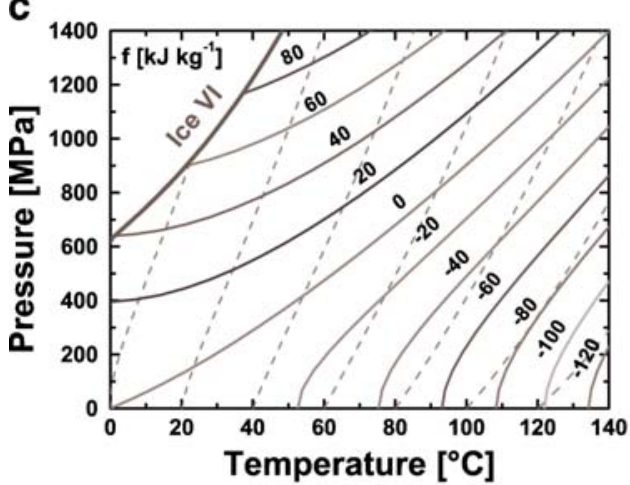

e

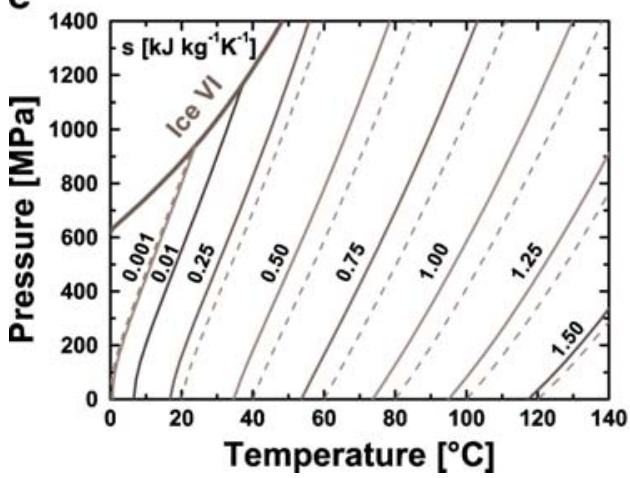

In Figure $1 b$, the density, $\rho$, of water with adiabatic lines due to compression in the $\mathrm{p}-\mathrm{T}$ landscape is shown. At high pressures, the compressibility decreases and there is a volume contraction of $10 \%, 17 \%$, or $23 \%$ at 400,800 , or $1,400 \mathrm{MPa}$, respectively.

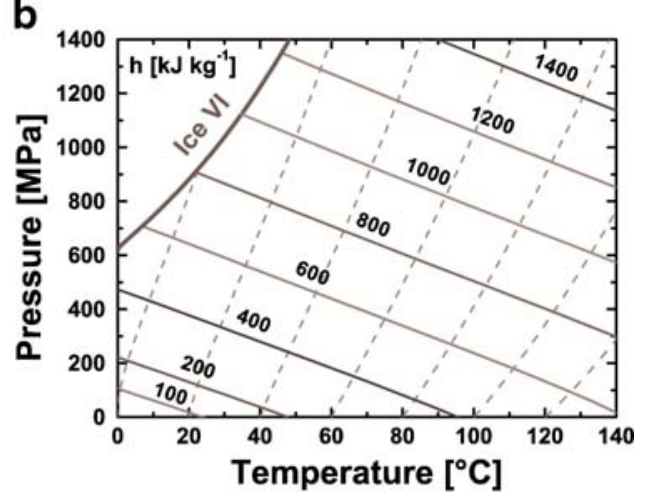

d

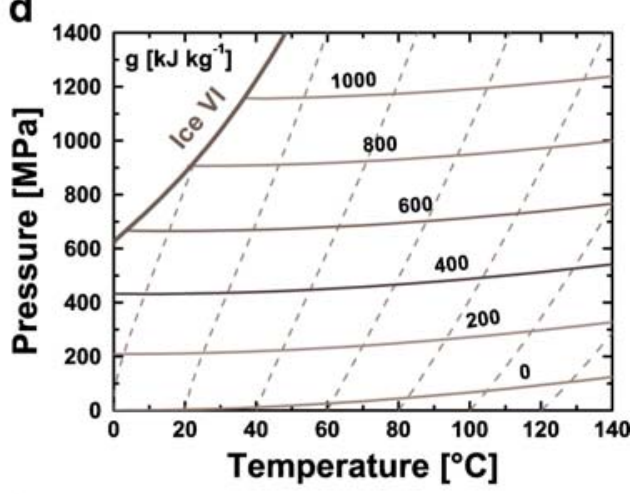

f

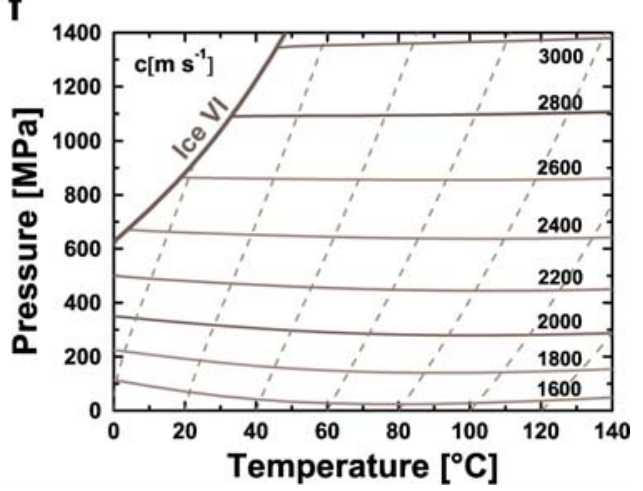


Fig. 3 Material properties with adiabatic lines due to compression (dashed line) of water in the $\mathrm{p}-\mathrm{T}$ landscape with isobaric heat capacity, $c_{p}(\mathbf{a})$, relative static permittivity, $\varepsilon(\mathbf{b})$, thermal expansion coefficient, $\alpha_{\mathrm{p}}(\mathbf{c})$, and isothermal compressibility, $\beta_{\mathrm{T}}(\mathbf{d})$
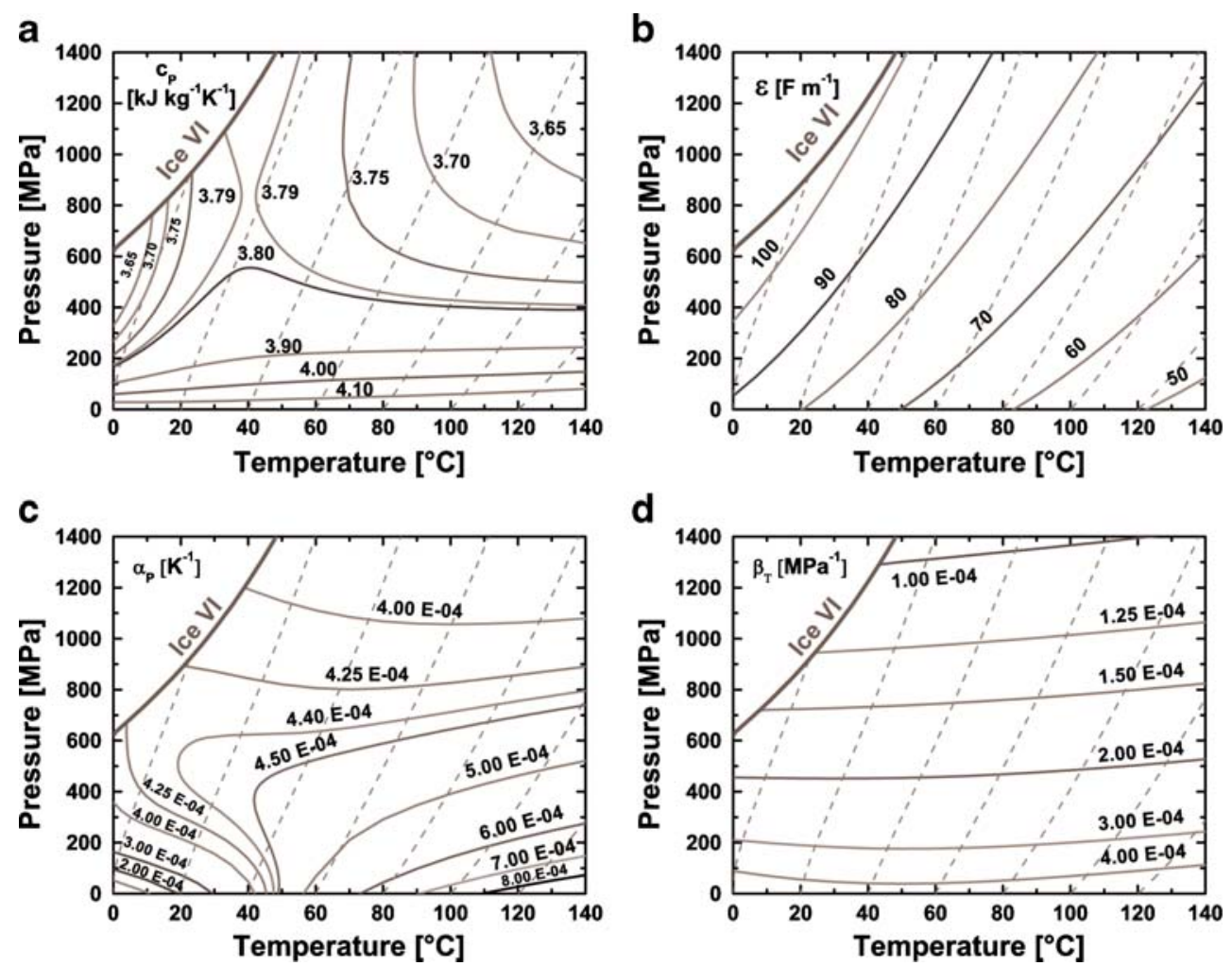

d

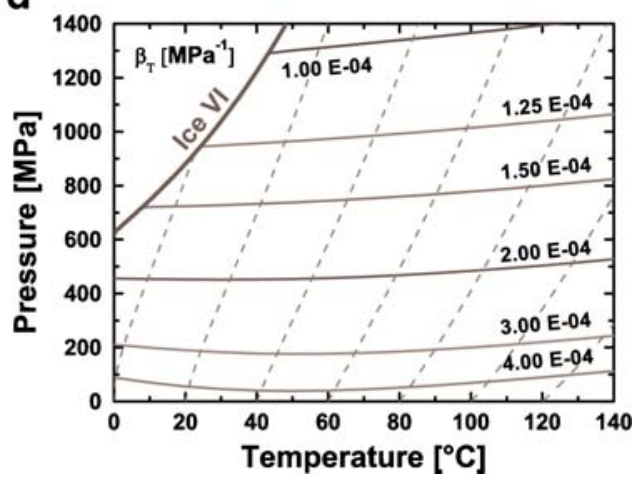

Figure 2 presents the $\mathrm{p}-\mathrm{T}$ landscape of fundamental thermodynamic parameters of water with (a) internal energy, $u$, (b) enthalpy, $h$, (c) Helmholtz free energy, $f$, (d) Gibbs free energy, $g$, (e) entropy, $s$, and (f) the speed of sound, $c$. The four thermodynamic potentials, internal energy, enthalpy, Helmholtz free energy, and Gibbs free energy, are all pressure- and temperature-dependent (Figure $2 \mathrm{a}-\mathrm{d}$ ) and have the dimensions of energy. They describe the amount of potential energy in a thermodynamic system when it is subjected to certain constraints. The internal energy is the energy needed to create a system. In Figure 2a, all isotherms show a decreasing inner energy, $u$, with pressure because of volume contraction.

The enthalpy is the energy needed to create a system plus the work needed to make room for it. Adiabatic lines in Figure $2 \mathrm{~b}$ show a higher increase of the enthalpy, $h$, because of the heat of compression in comparison to the isotherms.

All thermodynamic properties of water in this communication are based on the IAPWS-95 formulation, ${ }^{4}$ which is in the form of a fundamental equation explicit in the Helmholtz free energy, $f$. The Helmholtz free energy is the energy needed to create a system minus the energy you can get from the environment. Pressure is steadily increasing and temperature is steadily decreasing the Helmholtz free energy, $f$ (Figure 2c).

The Gibbs free energy is the total energy needed to create a system and the work needed to make room for it minus the energy you can get from the environment. In
Figure $2 \mathrm{~d}$, the strong pressure and low temperature dependence of the specific Gibbs free energy, $g$, is obvious. The Gibbs function of free energy, $\mathrm{d} G(T, p)$, is the fundamental equation for a system where pressure and temperature are the independent variables.

The difference in the free energy $\Delta G(T, p)$ is used to explain and model the elliptical shape of transition phenomena, e.g., protein denaturation ${ }^{11}$ or inactivation of microorganisms. ${ }^{12}$

The entropy is a measure of the disorder of a system. The entropy $\mathrm{s}$ is increased when ice is melted because of the increase in the disaggregation of the molecules of the body of

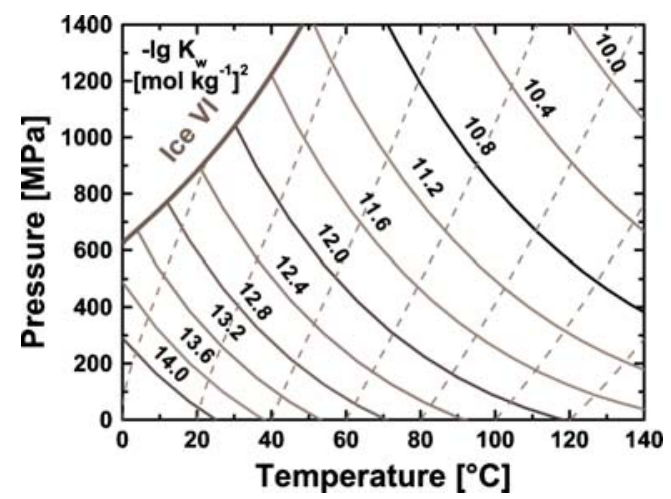

Fig. 4 Dissociation equilibrium shift [negative logarithm of the ion product $\left.K_{\mathrm{W}}\left(\mathrm{mol} \mathrm{kg}^{-1}\right)^{2}\right]$ in pure water under different $\mathrm{p}-\mathrm{T}$ conditions with adiabatic lines due to compression (dashed line; according to Marshall and Franck $\left.^{7}\right)^{14}$ 
Fig. 5 Transport properties with adiabatic lines due to compression (dashed line) of water in the $\mathrm{p}-\mathrm{T}$ landscape with thermal conductivity, $\lambda$ (a) and dynamic viscosity, $\eta$ (b)

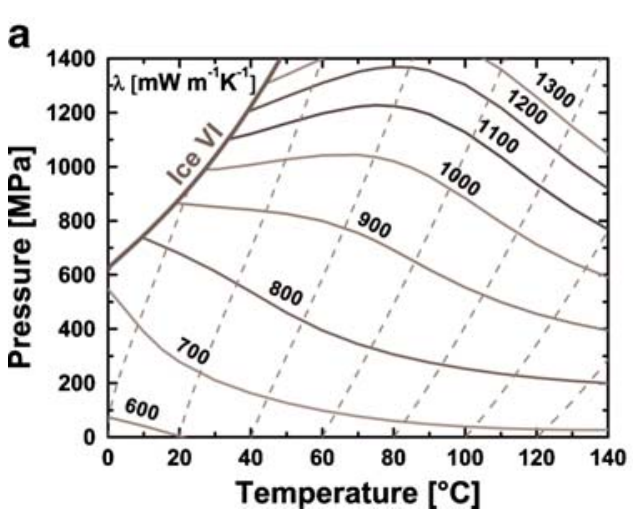

ice. At higher temperatures up to $140{ }^{\circ} \mathrm{C}$, the specific entropy $\mathrm{s}$ is also steadily increased. Iso-entropy and adiabatic lines are equal (Figure 2e) because adiabatic processes are reversible. According to the second fundamental theorem of thermodynamic, $\mathrm{d} s$ during reversible processes is zero.

The speed of sound, $c$, describes the velocity of the vibration that travels through an elastic medium, in this case water, as a wave (Figure 2f). It shows strong pressure and very low temperature dependencies (Figure 2f).

Figure 3 presents the $\mathrm{p}-\mathrm{T}$ landscape of material properties of water with (a) isobaric heat capacity, $c_{\mathrm{p}}$, (b) relative static permittivity, $\varepsilon$, (c) isobaric thermal expansion coefficient, $\alpha_{\mathrm{p}}$, and (d) isothermal compressibility, $\beta_{\mathrm{T}}$.

The heat capacity, $c_{\mathrm{p}}$, shows a strong decrease when increasing the pressure, but features only a very small change from $500 \mathrm{MPa}$ between $30^{\circ} \mathrm{C}$ and $60^{\circ} \mathrm{C}$ (Figure 3a). Hence, high-pressure processes at moderate temperatures for pasteurization and high-pressure thermal processes at temperatures over $100{ }^{\circ} \mathrm{C}$ for sterilization show different pressure dependencies of the heat capacity, $c_{\mathrm{p}}$.

The relative static permittivity, $\mathcal{E}$, has importance in the calculation of ionic reactions ${ }^{13}$ and shows noticeable changes with pressure and temperature (Figure $3 b$ ).

The thermal expansion coefficient, $\alpha_{\mathrm{p}}$, and the coefficient of compressibility, $\beta_{\mathrm{T}}$, are most important in the calculation of adiabatic heating as a result of compression. $\beta_{\mathrm{T}}$ as an intrinsic physical property of the material exhibits a high variability in gases, liquids, and solids and shows an extensive decrease with pressure at all temperatures.

The dissociation equilibrium shift in water showed also large variations with pressure and temperature (Figure 4). Pure water is neutral $\left(\left[\mathrm{H}_{3} \mathrm{O}^{+}\right]=\left[\mathrm{OH}^{-}\right]\right)$, and the negative logarithm of $K_{\mathrm{W}}$ has to be divided by two (according to Eq. 5) to obtain the $\mathrm{pH}$ or $\mathrm{pOH}$ value. During the shift of the dissociation equilibrium, the $\mathrm{pH}$ value would be changed with all reaction partners, but no change of the concentration difference on one site occurs during the reaction. Under pressure, there are increased oxonium and hydroxide concentrations, but still "neutral" conditions. Consequently, the $\mathrm{pH}$ shift alone cannot exactly describe the dissociation equilibrium shift, and thus, the $\mathrm{p} K_{\mathrm{a}}$ shift should be used. ${ }^{14}$

An important aspect for basic research studies under pressure is that commonly used buffer solutions showed different shifts of the dissociation equilibrium. The diversity of $\mathrm{p} K_{\mathrm{a}}$ shifts in buffer solutions resulted mainly from the different dissociation reactions and, consequently, different standard molar enthalpies $\left(\Delta_{\mathrm{r}} H^{0}\right)$ or reaction volumes $(\Delta V){ }^{14}$

Figure 5 shows the $\mathrm{p}-\mathrm{T}$ landscape of transport properties with (a) thermal conductivity, $\lambda$, and (b) dynamic viscosity, $\eta$. The thermal conductivity, $\lambda$, has a strong pressure dependence and improves the heat transfer in and to the product during pressure build-up as well as dwell time. At molecular processes, the dynamic viscosity, $\eta$ (Figure $5 b$ ), has an important role and shows strong temperature dependence.

On the basis of the first law of thermodynamics, after compression of $1 \mathrm{~kg}$ water up to $1,400 \mathrm{MPa}$, a maximum volumetric work of $130 \mathrm{~kJ} \mathrm{~kg}^{-1}$ at $140{ }^{\circ} \mathrm{C}$ is performed on the system according to Eq. 6 .

In Figure 6, the specific volumetric work, $w$, in pure water $(p, T)$ is presented using previous results of this communication with the isothermal compressibility, $\beta_{\mathrm{T}}(p, T)$ (Figure $3 \mathrm{~d}$ ) and the specific volume $v(p, T)\left[v(p, T)=\rho^{-1}(p, T)\right]$ (Figure 1b).

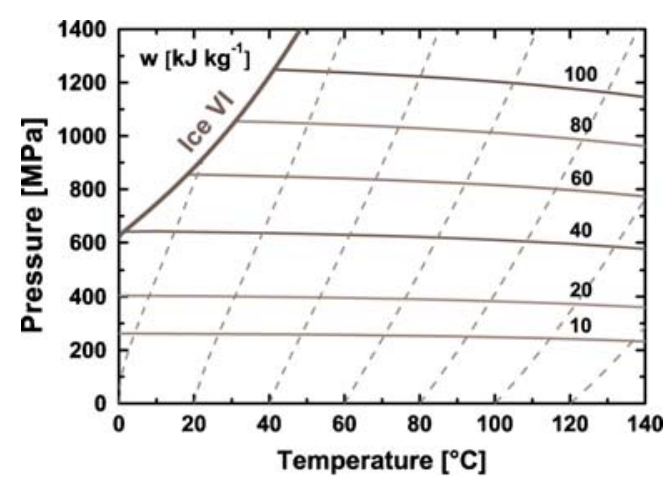

Fig. 6 Specific volumetric work $w\left(\mathrm{~kJ} \mathrm{~kg}^{-1}\right)$ with adiabatic lines due to compression (dashed line) of water in the $\mathrm{p}-\mathrm{T}$ landscape according to Eq. 6 
The high pressure and low temperature dependence resulted from the functional relationships of the isothermal compressibility, $\beta_{\mathrm{T}}(p, T)$, and the specific volume, $v(p, T)$.

\section{Conclusion}

The generated $\mathrm{p}-\mathrm{T}$ diagrams give a concise overview about the pressure and temperature dependencies of pure water. Complete different pressure and temperature dependencies of the investigated properties can be observed. This differences show the complexity of medium properties during high-pressure processing with or without higher temperatures. The modeled data are also interesting for other thermal processes (e.g., pasteurization and sterilization by heat) or technologies (e.g., microwave or ohmic heating). Currently, there are only limited data for food or other matrices available. Experimental investigations and the formulation of functional relationships, for example by regression methods, have to be performed for such kinds of media to clarify the different behavior at process conditions.

\section{Notation}

$\begin{array}{ll}G & \text { Gibbs free energy }\left(\mathrm{kJ} \mathrm{kg}^{-1}\right) \\ \Delta_{\mathrm{r}} H^{0} & \begin{array}{l}\text { Standard molar enthalpy }\left(\mathrm{kJ} \mathrm{mol}^{-1}\right) \\ \text { IAPWS }\end{array} \\ & \begin{array}{l}\text { International Association for the Properties of } \\ \text { Water and Steam }\end{array} \\ K_{\mathrm{W}} & \text { Ion product of water }\left[\left(\mathrm{mol} \mathrm{kg}^{-1}\right)^{2}\right] \\ \mathrm{NIST} & \text { National Institute of Standards and Technology } \\ T & \text { Temperature }\left({ }^{\circ} \mathrm{C} \text { or } \mathrm{K}\right) \\ \Delta V & \text { Reaction volume at atmospheric pressure } \\ & \left.\text { (cm }{ }^{3} \text { mol }{ }^{-1}\right) \\ c & \text { Speed of sound (m s }) \\ c_{\mathrm{p}} & \text { Isobaric heat capacity }\left(\mathrm{kJ} \mathrm{kg}^{-1} \mathrm{~K}^{-1}\right) \\ d & \text { Derivate } \\ f & \text { Specific Helmholtz energy }\left(\mathrm{kJ} \mathrm{kg}^{-1}\right) \\ g & \text { Specific Gibbs free energy }\left(\mathrm{kJ} \mathrm{kg}^{-1}\right) \\ h & \text { Specific enthalpy }\left(\mathrm{kJ} \mathrm{kg}^{-1}\right) \\ p & \text { Pressure (MPa) } \\ \mathrm{pH} & \text { Decadic logarithm of the activity of } \\ & \text { hydroxonium ions }[-]\end{array}$

$\mathrm{pK}_{\mathrm{a}} \quad$ Decadic logarithm of acid dissociation constant $[-]$

pOH Decadic logarithm of the activity of hydroxide ions [-]

$s \quad$ Specific entropy $\left(\mathrm{kJ} \mathrm{kg}^{-1} \mathrm{~K}^{-1}\right)$

$u \quad$ Specific internal energy $\left(\mathrm{kJ} \mathrm{kg}^{-1}\right)$

$v \quad$ Specific volume $\left(\mathrm{m}^{3} \mathrm{~kg}^{-1}\right)$

$w \quad$ Volumetric work $\left(\mathrm{kJ} \mathrm{kg}^{-1}\right)$

$\alpha_{\mathrm{p}} \quad$ Isobaric expansion coefficient $\left(\mathrm{K}^{-1}\right)$

$\beta_{\mathrm{T}} \quad$ Isothermal compressibility $\left(\mathrm{MPa}^{-1}\right)$

$\Delta \quad$ Increment or gradient

$\varepsilon \quad$ Relative static permittivity [-]

$\eta \quad$ Dynamic viscosity ( $\mu \mathrm{Pa} \mathrm{s}$ or $\mathrm{mPa} \mathrm{s})$

$\lambda$ Thermal conductivity $\left(\mathrm{mW} \mathrm{m}^{-1} \mathrm{~K}^{-1}\right.$ or $\mathrm{W} \mathrm{m} \mathrm{m}^{-1}$ $\mathrm{K}^{-1}$ )

$\begin{array}{ll}\rho & \text { Density }\left(\mathrm{kg} \mathrm{m}^{-3}\right) \\ \partial & \text { Partial derivative }\end{array}$

\section{References}

1. W.P. Larson, T.B. Hartzell, H.S. Diehl, J. Infect. Dis. 22, 271-279 (1918)

2. D. Margosch, M.A. Ehrmann, R. Buckow et al., Appl. Environ. Microbiol. 72, 3476-3481 (2006). doi:10.1128/AEM.72.5.34763481.2006

3. A. Mathys, K. Reineke, V. Heinz, D. Knorr, High. Press. Res. (2009) (in press). doi:10.1080/08957950802526469

4. W. Wagner, A. Pruss, J. Phys. Chem. Ref. Data 31, 387-535 (2002). doi:10.1063/1.1461829

5. P.W. Bridgman, Proc. Am Acad. Arts Sci. 47, 439-558 (1912)

6. D.P. Fernandez, A.R.H. Goodwin, E.W. Lemmon et al., J. Phys. Chem. Ref. Data 26, 1125-1166 (1997)

7. W.L. Marshall, E.U. Franck, J. Phys. Chem. Ref. Data 10, 295304 (1981)

8. J. Kestin, J.V. Sengers, B. Kamgarparsi, J.M.H.L. Sengers, J. Phys. Chem. Ref. Data 13, 175-183 (1984)

9. A. Ardia, PhD thesis, Berlin University of Technology, 2004

10. P.W. Bridgman, Proc. Am. Acad. Arts Sci. 47, 441-558 (1911)

11. L. Smeller, BBA-Protein Struct. M. 1595, 11-29 (2002)

12. V. Heinz, D. Knorr, in Ultra high pressure treatments of foods, ed. by M.E.G. Hendrickx, D. Knorr (Kluwer, New York, 2002)

13. P. Debye, E. Hueckel, Phys. Z. 24, 185-206 (1923)

14. A. Mathys, R. Kallmeyer, V. Heinz, D. Knorr, Food Control 19, 1165-1173 (2008). doi:10.1016/j.foodcont.2008.01.003 